\title{
Do the calcifications in the thyroid gland predict malignancy?
}

\author{
Gungor B, Polat AK, Polat C, Seren D, Erzurumlu K \\ Ondokuz Mayis University, Faculty of Medicine, Department of General Surgery, Samsun, Turkey. \\ bgungor@omu.edu.tr
}

\begin{abstract}
Background: The purpose of this study was to determine the relationship between calcifications in the thyroid gland and malignant thyroid lesions.

Methods: From June 2005 - May 2010, 169 patients, who had been operated on for thyroidectomy, were evaluated. The demographic findings were analyzed with regard to ultrasonographic and histopathologic calcifications. The relationship between calcifications and malignant and benign thyroid lesions was statistically determined by SPSS 10.01 version of Z-test and Chi-square test.

Results: Microcalcifications were found in 54 patients (31.95\%). Macrocalcification was found in one patient $(0.59 \%)$. Malignancy was determined in 29 patients $(17.16 \%)$. The rate of malignancy in patients with calcifications was $17 / 55(30.91 \%)$. The diagnosis was nodular colloidal goiter in 38 patients $(38 / 55,69.09 \%)$ with calcifications. The rate of calcification in malignant patients was 17/29 (58.62\%). The rate of malignancy in patients without calcification was $12 / 114(10.52 \%)$. The difference between the rate of malignancy in patients with calcification and the rate of malignancy in patients without calcification was statistically significant (Z-test, $p<0.001)$. Conclusion: Microcalcifications of the thyroid gland could predict malignant thyroid disease. They should be strictly evaluated by all thyroid cancer diagnostic modalities and surgical treatment should also be considered (Tab. 4, Ref. 29). Full Text in PDF www.elis.sk.

Key words: calcifications, thyroid gland, malignancy, microcalcifications, malignant thyroid lesions.
\end{abstract}

The high prevalence of thyroid nodules and the risk of malignancy are serious problems in thyroid surgery. Approximately 3 $-7 \%$ of adult populations have palpable thyroid nodules; however, only $5 \%$ of clinically detected nodules are malignant $(1,2,3)$.

Although the incidence of well-differentiated thyroid carcinoma has been reported in up to $36 \%$ in autopsy series, it is proven histopathologically in about $10 \%$ of patients who undergo surgery. Fine-needle aspiration cytology samples are insufficient for the diagnosis, and up to $28 \%$ of the patients studied showed nondiagnostic and false positive results $(4,5)$.

Patients with calcifications in the thyroid gland are still a clinical dilemma. When a calcification is detected in the gland, a question arises as to whether this is a predictive sign for malignancy or not. Microcalcifications were reported in $60 \%$ of malignant nodules (6). The specificity of microcalcification for malignancy increases in young patients who exhibit single nodules with a snow-storm pattern on ultrasound (7). On the other hand, though the specificity of microcalcifications increase to $95 \%$ for papillary cancer, the sensitivity is low; $29-59 \%$ of papillary carcinomas are seen with microcalcifications (8).

Calcifications may be easily recognized by thyroid ultrasonography (US) or histopathological examination. Although high frequency ultrasound transducers increased the sensitivity of ul-

Ondokuz Mayis University, Faculty of Medicine, Department of General Surgery, Samsun, Turkey

Address for correspondence: B. Gungor, MD, Ondokuz Mayis University, Faculty of Medicine, Department of Surgery, 55139, Kurupelit, Samsun, Turkey.

Phone: $+903623121919 / 3673$, Fax: +903624576041 trasonography, they are not sufficient to determine the malignancy. Calcifications can be in macro- or microcalcification form. Macrocalcifications are greater than $2 \mathrm{~mm}$, and are commonly seen due to trauma or inflammatory process; they are rarely associated with medullary cancer. Microcalcifications are less than $2 \mathrm{~mm}$ and have been described in literature as "snowstorm," "peripheral," "fine stippled psammomatous (FSP)," "fine,", "punctuate," "gross," and "coarse". Furthermore, these quantifications are not specific for malignancy $(1,7)$.

While most of the authors agree that microcalcification is a predictive factor for malignant thyroid lesion, there are some authors who disagree.

In this study, we tried to determine the relationship between calcifications in the thyroid gland and thyroid malignancy.

\section{Patients and methods}

Study participants included 178 who had undergone thyroidectomy between June 2005 and May 2010 at Ondokuz May1s University, Faculty of Medicine, Department of Surgery. All 178 patients were operated upon by a single surgeon. The demographic data and the ultrasonographic and histopathologic findings were analyzed. The ultrasonographic examination was made by using the Toshiba Aplio 80 apparatus, with a $7.5 \mathrm{mHz}$ linear probe. The calcifications were quantified as peri- and intranodular, and micro- $(<2 \mathrm{~mm})$ and macrocalcifications ( $>2 \mathrm{~mm})$. The histopathologic evaluation was made with haematoxylin-eosin staining. The blue-violet amorphous stainings of fine, coarse, peripheral and psammomatous types, inside and around the thyroid nodules were defined as calcifications. 
Tab. 1. The distribution of operated patients and thyroid cancers according to sex.

\begin{tabular}{lcc}
\hline & Male & Female \\
\hline Number & 44 & 125 \\
Malignancy & 10 & 19 \\
\hline
\end{tabular}

Nine patients, whose ultrasonographic and histopathologic findings could not be determined, were excluded. In 135 of the remaining 169 patients, both ultrasonographic and histopathological findings were analyzed. In 34 patients, only histopathologic findings were analyzed because the ultrasonographic findings were not available. The relationship between the calcifications was determined using ultrasonography and/or histopathology, and the malignancy was determined by fine-needle aspiration biopsy or surgical specimen, and was retrospectively and statistically analyzed. The differences and the significances of the results were analyzed using the SPSS 10.01 verrsion of the Z-test and the Chisquare test in SPSS 10.01 version.

\section{Results}

Of the 178 participants, 44 patients $(26.04 \%)$ were male and $125(73.96 \%)$ were female. The mean age of patients was 48.23 \pm 13.087 (age range 20-94). Ten males and 19 females were diagnosed with thyroid cancer (Tab. 1). The difference between the rates of malignancy in males and females was not statistically significant ( $p=0.255$ ) but the rate of malignancy is higher in males ( $22.74 \%$ for males versus $15.20 \%$ for females). However, the rate of nodules in males who had undergone surgery was lower when compared with females $(26.04 \%$ for males versus $73.96 \%$ for females).

Ten patients who had undergone surgery at another center and diagnosed with nodular goiter were referred to our hospital with the histopathological diagnosis of malignancy. In these patients, due to insufficient ultrasonographic evaluation and unavailable preoperative ultrasonographic findings, only the histopathologic findings were analyzed with regard to the aspect of calcifications.

Out of 135 patients, calcifications were determined in 34 patients $(25.19 \%)$ in whom both ultrasonographic and histopathologic findings were evaluated. Of these 34 patients, in 21 patients $(61.76 \%)$, only the histopathologic findings were evaluated (Tab. 2).

Microcalcifications were determined in 54 of 169 patients $(31.95 \%)$, a macrocalcification was determined in one patient $(0.59 \%)$, and malignancy was determined in 29 patients $(17.16 \%)$. The histopathologic diagnosis of the patient with macrocalcification was benign (Tab. 3). Fourteen of 20 patients (70 \%) with papillary cancer had histopathologic calcifications (Tab. 4).
Tab. 3. The basic data in the series $(n=169)$.

\begin{tabular}{lcc}
\hline & & $\%$ \\
\hline $\begin{array}{l}\text { Male/Female } \\
\text { Age }\end{array}$ & $44 / 125$ & $26.04-73.96$ \\
$\begin{array}{l}\text { Calcification } \\
\quad \text { Micro }\end{array}$ & 54 & \\
$\quad$ Macro & 1 & 31.95 \\
$\quad$ Total & 55 & 0.59 \\
Malignancy & 29 & 32.54 \\
$\begin{array}{l}\text { Rate of malignancy in patients } \\
\text { with calcification }\end{array}$ & $17 / 55$ & 17.16 \\
$\begin{array}{l}\text { Rateof calcification in patients } \\
\text { with malignancy }\end{array}$ & $17 / 29$ & $30.91^{*}$ \\
$\begin{array}{l}\text { Rate of malignancy in patients } \\
\text { without calcification }\end{array}$ & $12 / 114$ & $58.62 *$ \\
* $\mathrm{p}<0.001$ & & $10.52^{*}$ \\
& & \\
& &
\end{tabular}

Tab. 4. The distribution of histopathologic diagnosis and calcification according to the type of malignancy in the patients with malignancy and calcification.

\begin{tabular}{lcc}
\hline & $\mathrm{n}$ & Calcification $-\%$ \\
\hline Papillary cancer & 20 & $14-70 \%$ \\
Papillary cancer- follicular variant & 2 & - \\
Follicular cancer & 2 & - \\
Medullary cancer & 2 & $1-50 \%$ \\
Hurthle cell neoplasia & 1 & $1-100 \%$ \\
Anaplastic carcinoma & 1 & $1-100 \%$ \\
Epidermoid carcinoma & 1 & - \\
\hline Total & 29 & $17-58.62 \%$ \\
\hline
\end{tabular}

The rate of malignancy in patients with calcifications was 17/55 (30.91\%). Of the 55 patients with calcifications, 38 (69.09\%) were diagnosed with "nodular colloidal goiter" (Tab. 3). The rate of calcification in patients with malignancy was $17 / 29$ (58.62\%). The rate of malignancy in patients without calcification was $12 / 114$ (10.52\%) (Tab. 3). The difference between the rate of malignancy in patients with calcification and the rate of malignancy in patients without calcification was statistically significant (z-test, $\mathrm{p}<0.001$ ).

\section{Discussion}

Thyroid cancer is a relatively uncommon disease which constitutes about $0.5-2 \%$ of all malignancies (9). Calcification detected by thyroid ultrasound represents a risk factor for malignancy but it is of limited use as a sole marker of malignancy (10). Ultrasound is an ideal imaging modality of detecting the thyroid nodules. It is easy to perform, widely available, non-invasive, and affordable. The advantages of using ultrasound in the diagnosis of thyroid disease (both malign and benign) are that it allows for the detection and characterization of thyroid malignancies, cervical nodal

Tab. 2. Distribution of calcifications in US and histopathologic examination according to the types of malignancy.

\begin{tabular}{lcccc}
\hline Types of determination of calcifications & Number & Papillary ca & Medullary ca & Hurthle Cell Neoplasia \\
\hline Calcifications in only HE & 21 & 4 & 1 & 1 \\
Calcifications in both USG and HE & 34 & 10 & & 1 \\
\hline
\end{tabular}

USG = ultrasonography, $\mathrm{HE}=$ histopathologic examination 
metastases, and loco-regional recurrence, as well as provides image-guided biopsy for fine-needle aspiration cytology $(11,12)$.

On the other hand, ultrasonographic findings of thyroid cancers are well described in literature. Calcification, irregular shape, solid hypoechogenity, absence of halo, intranodular hypervascularity and changing margin (blurred or ill-defined), alone or in combination of two or more are reported as predictive factors of thyroid cancers (13-24).

Calcification in the thyroid can be detected by US or histopathological examinations. Studies have found that 16.95-78.8\% of patients have calcifications in their thyroid $(1,6,10,25)$. In our study, the rate of calcification was found to be $32.54 \%$ by US or histopathological examinations. These results correlated with the findings presented in literature. In our study, the rate of calcification in malignant lesions was $58.62 \%$. This is a significantly higher number than the rate of overall calcifications. However, the rate of malignancy in calcifed lesions is not as high (only $30.91 \%$ ). Therefore, when a calcification is determined, malignancy should be suspected; however that does not mean that all calcifications are malignant.

Macrocalcifications of the thyroid have been reported unrelated to malignancies, except with regard to medullary cancer. In literature, microcalcifications are classified as "snowstorm," "peripheral," "fine stippled psammomatous (FSP)," "fine," and "punctuate" $(7,14,15,16,25,26)$. All types of microcalcifications have been reported as predictive factors for thyroid cancer. Commonly reported "coarse," "dysmorphic," or "curvilinear" calcifications indicate benign lesions of the thyroid gland (2). Additionally, Park (9) found that interruptions of peripheral calcifications were more common in malignant nodules ( $84 \%$ ) vs. benign ones (53\%). Furthermore, the thickening of peripheral calcifications was seen more frequently in malignant nodules (64\% vs $11 \%$ ) than in benign ones.

Most of the authors agree that calcification is a predictive factor for thyroid malignancies $(1,7,8,9,10,25,26,27,28)$, while a few authors disagree $(6,29)$. According to Chan $(11)$, hypoechoic texture (86\%), microcalcifications (42\%), well-defined margins (47\%), and intrinsic hypervascularity (69\%) are common sonographic features of papillary carcinoma. He also found the rate of microcalcifications to be $69 \%$ and the rate of coarse calcifications $17 \%$. In our study, the rate of microcalcifications was $31.95 \%$. Microcalcifications associated with other findings were highly specific for thyroid malignancies but they were only present in half of the malignancies. When positive findings of malignancy are studied in parallel, sensitivity and specificity will increase to $81 \%$ (12).

Chen reported (10) that the incidence of calcification in patients with thyroid carcinoma was significantly higher than in those with benign lesions $(54.17 \%$ vs $26.87 \%$; $<<0.005)$. Chammas (1) has found that microcalcifications were highly specific for malignancy and were present in $61 \%$ of the malignant nodules $(p=0.001)$. Wang (26) has reported that in his series of 332 cases, FSP calcification was more significant in malignant nodules than was non-FSP calcification ( $\mathrm{p}=0.001)$. González (27) has showed that most cases with microcalcifications were malignant compared to cases without calcifications ( $60 \%$ vs $1.7 \%$, p < 0.001 ). Khoo's study (28) shows that intrathyroideal calcification with malignancy occurred at a rate of $59.2 \%$.
Wong has reported that fine calcification is seen in papillary carcinoma in $25-40 \%$ of cases (2). As a predictive sign of malignancy, the specificity and positive predictive value of calcification were reported as $93 \%$ and $70 \%$, respectively (6). Our study found the calcification rate to be $70 \%$ in papillary cancer. The rate of calcifications in other types of thyroid cancer such as medullary, Hurthle cell or anaplastic carcinoma is higher; only four patients with these types of concerns were reported in our series (Table 2). If greater numbers of patients could be analyzed in future studies, the statistical significance of calcifications could be determined.

The sensitivity and specificity of microcalcifications in thyroid malignancies has been found to be $32.28-78.80 \%$ and $61.30-$ $100 \%(3,6,7,10,12,25)$. However, macrocalcification has been found to be less sensitive (9.7\%) (25).

In our study, calcifications of thyroid malignancies are found approximately six times more often than those of benign diseases $(\mathrm{p}<0.001)$. This finding also correlates with literature.

In conclusion, microcalcification of the thyroid gland is a predictive factor for malignancy. When detected, malignancy should be suspected and all diagnostic modalities including fine-needle aspiration biopsy and surgical treatment should be considered.

\section{References}

1. Chammas MC, de Araujo Filho VJ, Moysés RA, Brescia MD, Mulatti GC, Brandão LG, Cerri GG, Ferraz AR. Predictive value for malignancy in the finding of microcalcifications on ultrasonography of thyroid nodules. Head Neck 2008; 30 (9): 1206 - 1210.

2. Wong KT, Ahuja AT. Ultrasound of thyroid cancer. Cancer Imaging 2005; 5 (1): $157-166$.

3. Seiberling KA, Dutra JC, Grant T, Bajramovic S. Role of intrathyroidal calcifications detected on ultrasound as a marker of malignancy. Laryngoscope 2004; 114 (10): 1753 - 1757.

4. Ross DS. Evaluation of the thyroid nodule. J Nucl Med 1991; 32: 2181 -2192 .

5. Mittendorf E, Tamarkin S, Mc Henry C. The results of ultrasound guided fine -needle aspiration biopsy for evaluation of nodular thyroid disease. Surgery 2002; 132: 648 - 654 .

6. Takashima S, Fukuda H, Nomura N, Kishimoto H, Kim T, Kobayashi T. Thyroid nodules: re-evaluation with ultrasound. J Clin Ultrasound 1995; 23 (3): $179-184$.

7. Iannuccilli JD, Cronan JJ, Monchik JM. Risk for malignancy of thyroid nodules as assessed by sonographic criteria: the need for biopsy. J Ultrasound Med 2004; 23 (11): 1455 - 1464.

8. Kakkos SK, Scopa CD, Chalmoukis AK, Karachalios DA, Spiliotis JD, Harkoftakis JG, Karavias DD, Androulakis JA, Vagenakis AG. Relative risk of cancer in sonographically detected thyroid nodules with calcifications. J Clin Ultrasound 2000; 28 (7): 347 - 352.

9. Park M, Shin JH, Han BK, Ko EY, Hwang HS, Kang SS, Kim JH, Oh YL.Sonography of thyroid nodules with peripheral calcifications. J Clin Ultrasound 2009; 37 (6): 324 - 328.

10. Chen G, Zhu XQ, Zou X, Yao J, Liang JX, Huang HB, Li LT, Lin LX. Retrospective analysis of thyroid nodules by clinical and pathological characteristics, and ultrasonographically detected calcification correlated to thyroid carcinoma in South China. Eur Surg Res 2009; 42 (3): 137 - 142. 
11. Chan BK, Desser TS, McDougall IR, Weigel RJ, Jeffrey RB Jr.Common and uncommon sonographic features of papillary thyroid carcinoma. J Ultrasound Med 2003; 22 (10): 1083 - 1090.

12. Peccin S, de Castsro JA, Furlanetto TW, Furtado AP, Brasil BA, Czepielewski MA. Ultrasonography: is it useful in the diagnosis of cancer in thyroid nodules? J Endocrinol Invest 2002; 25 (1): 39 - 43.

13. Cappelli C, Castellano M, Pirola I et al. The predictive value of US findings in the management of thyroid nodules. Q J Med 2006; 100: 29 - 35 .

14. Kim E, Park CS, Chung WY et al. New sonographic criteria for recommending fine-needle aspiration biopsy of nonpalpable solid nodules of the thyroid. AJR Am J Roentgenol 2002; 178: 687 - 691.

15. Koike E, Noguchi S, Yamashita $H$ et al. Ultrasonographic characteristics of thyroid nodules: prediction of malignancy. Arch Surg 2001; 136: $334-337$.

16. Leenhardt L, Menegaux F, Franc B et al. Selection of patients with solitary thyroid nodules for operation. Eur J Surg 2002; 168: 236 - 241.

17. Yousem DM, Scheff AM. Thyroid and parathyroid. In: Som PM, Curtin HD, editors. Head and Neck Imaging. third edn. St Louis: Mosby; 1996, $953-975$.

18. McIvor NP, Freeman JL, Salem S. Ultrasonography of the thyroid and parathyroid glands. ORL J Otorhinolaryngol Relat Spec 1993; 55: $303-308$.

19. Rago T, Vitti P, Chiovato L, et al. Role conventional ultrasonography and colour flow Doppler sonography in predicting malignancy in 'cold' thyroid nodules. Eur J Endocrinol 1998; 138: 41 - 46.

20. Solbiati L, Livraghi T, Ballarati E, Ierace T, Crespi L. Thyroid gland. In: Solbiati L, Rizzatto G, editors. Ultrasound of Superficial Structures. London: Churchill Livingstone, 1995, $49-85$.
21. Simeone JF, Daniels GH, Mueller PR, et al. High resolution real time sonography of the thyroid. Radiology 1982; 145: $431-435$.

22. Solbiati L, Volterrani L, Rizzatto G, et al. The thyroid gland with low uptake lesions: evaluation with ultrasound. Radiology 1985; 155: 187- 191.

23. Propper RA, Skolnick ML, Weinstein BJ, Dekker A. The nonspecificity of the thyroid halo sign. J Clin Ultrasound 1989; 8: 129 - 132.

24. Noyek AM, Finkelstein DM, Kirsch JC. Diagnostic imaging of the thyroid gland. In: Falk SA, editor. Thyroid Disease: Endocrinology, Surgery, Nuclear Medicine, and Radiotherapy. New York: Raven Press, 1990, $952-975$.

25. Moon WJ, Jung SL, Lee JH, Na DG, Baek JH, Lee YH, Kim J, Kim HS, Byun JS, Lee DH; Benign and malignant thyroid nodules: US differentiation - multicenter retrospective study. Radiology 2008; 247 (3): $762-770$.

26. Wang N, Xu Y, Ge C, Guo R, Guo K. Association of sonographically detected calcification with thyroid carcinoma. Head Neck 2006; 28 (12): 1077 - 1083 .

27. González-González A, Mate Valdezate A, Parra Arroyo A, Tenías Burillo JM. Diagnostic efficiency of sonographic findings of thyroid nodules in the detection of malignancy. Endocrinol Nutr 2010 May 4 [Epub ahead of print].

28. Khoo MLC, Sylvia L. Asa SL, Witterick IJ, FreemanJL. Thyroid calcification and its association with thyroid carcinoma. Head and Neck 2002; 24: 651 - 655 .

29. Yoon DY, Lee JW, Chang SK, Choi CS, Yun EJ, Seo YL, Kim KH, Hwang HS. Peripheral calcification in thyroid nodules: ultrasonographic features and prediction of malignancy. J Ultrasound Med 2007; 26 (10): 1349 - 1355; quiz 1356 - 1357. 